Daimon. Revista Internacional de Filosofía, Suplemento 5 (2016), 817-826

ISSN: 1130-0507 (papel) y 1989-4651 (electrónico)

http://dx.doi.org/10.6018/daimon/269091

\title{
Elogio de la melancolía: una historia marginal de la bilis negra
}

\author{
In praise of melancholy: \\ A marginal history of the black bile
}

\begin{abstract}
Resumen: Este ensayo se desarrolla a partir de la siguiente hipótesis: hay, por lo menos, dos historias posibles de la melancolía. No se trata, sin embargo, de historias indiferentes entre sí, sino más bien de historias entrecruzadas que pretenden ignorarse una a la otra, que se confunden, dialogan y se enfrentan a lo largo de su transcurso. Nos permitiremos elaborar una pequeña genealogía que nos permita comprender la forma en la que nacieron estas dos presuntas historias de la melancolía a las que hacemos referencia, y así mostrar las diferentes transformaciones por las cuales ha pasado la bilis negra, sustancia que ha sido asociada con fenómenos tan disímiles entre sí como lo patológico, la genialidad e, incluso, lo humorístico.
\end{abstract}

Palabras clave: Melancolía, bilis negra, locura, genialidad, humor, patología
JUAN HORACIO DE FREITAS*

\begin{abstract}
This essay rests upon the following statement: there are at least two possible stories of melancholy. It is not, however, about two unrelated stories, but rather about two intermingled stories pretending to ignore each other, fusing into each other, addressing each other and facing up to each other all along the process of being told. We will thus refer to a short genealogy that will allow us to understand how the two mentioned stories of melancholy have developed, and in so doing, we will show the different transformations the so called 'black bile' has gone through, a fact which is usually related to divergent phenomena such as pathology, genius and, even, humor.
\end{abstract}

Keywords: Melancholy, melancholia, black bile, madness, genius, humor, pathology.

Desde que Hipócrates en el siglo V a.C. describiera por primera vez en sus Aforismos la sintomatología patológica del exceso de un humor en el cuerpo humano ${ }^{1}$, se ha dado en el imaginario de Occidente una serie de tipologías temperamentales que encuentran sus raíces

Fecha de recepción: 21/04/2016. Fecha de aceptación: 12/09/2016.

* (Caracas, 1986) Doctorando en filosofía en la Universidad Complutense de Madrid (UCM). Magíster en Estudios Avanzados en Filosofía en la Universidad Complutense de Madrid (UCM). Licenciado en Filosofía en la Universidad Católica Andrés Bello (UCAB). Actualmente se encuentra haciendo su trabajo doctoral en torno al lugar del cinismo en las obras de Michel Foucault, y es investigador asociado del Centro de Investigaciones de la Facultad de Humanidades (CIFH) de la Universidad Católica Andrés Bello. Contacto: defreitas.jh@, gmail.com // jdefreit@ucm.es Ha publicado: "El cinismo: Un elogio a la desvergüenza”. En: Bajo Palabra. "Melancolía y flema": Consideraciones humoralistas en torno a la noción de melancolía en el «Origen del Trauerspiel alemán» de Walter Benjamin. En: Tópicos Revista de Filosofía No 45. 
en las entrañas del cuerpo humano y sus respectivos flujos. El así llamado humoralismo hipocrático se convirtió de inmediato, y a lo largo de veintitrés siglos, en un territorio inconmensurablemente fértil al que cuantiosísimos artistas y filósofos, desde Aristóteles ${ }^{2}$ a Burton $^{3}$, de Galeno ${ }^{4}$ a Ben Jonson ${ }^{5}$, de Rabelais ${ }^{6}$ a Kant $^{7}$; acudían para cultivar sus frutos. En su sentido primitivo, es decir, en ese sentido que nos ofrece la antropología del Corpus Hipocraticus, los humores sólo tienen lugar en el campo de lo estrictamente somático-nosológico; la causa de las enfermedades se debería siempre al incremento, disminución o deterioro de alguna sustancia humoral en el cuerpo. No existe en Hipócrates una teoría de los temperamentos, de los tipos psicológicos; empero, sí existe, como se dijo en las primeras líneas, un pequeño aforismo atribuido al médico de Coz que vincula uno de los cuatro humores de la doctrina humoralista, en este caso la bilis negra (melancholia), con determinados estados de ánimo, específicamente el temor y la tristeza ${ }^{8}$.

Nos topamos con el inicio de una historia de la melancolía más allá (o más acá) de lo fisiológico, es decir, con el inicio de una historia psicológica de la melancolía marcada por dos sensaciones fundamentalmente: el miedo y la tristeza. Podría uno imaginar que frente a semejante descripción psicológica que ofrece Hipócrates del melancólico, tan sombría, fúnebre y despectiva, el hombre atrabiliario sería visto casi como un enfermo, alguien que debe ser curado. Y quien lo imagine no estará equivocándose del todo. Ya San Isidoro de Sevilla dice en sus célebres Etimologías:

Se dice "malo" por la bilis negra, que los griegos llaman $\mu \varepsilon \lambda \alpha v$; de donde procede que se llame también melancólicos a los hombres que no sólo rehúyen el trato humano, sino que desconfían incluso de sus amigos queridos. ${ }^{9}$

Este tipo de descalificativos al "humor negro", incluso con justificaciones filológicas muy poco rigurosas, fue habitual durante toda la era medieval. Más allá del juicio moral que podría hacerse del melancólico, lo que consideramos importante destacar es la continua vinculación desde sus inicios con la tristeza y el temor, lo que permitió a los teólogos y demonólogos medievales observar al hombre con exceso de bilis negra como un poseído por el pecado capital de la acedia, por el demonio de la pereza o por el taedium cordis del que habla San Agustín. De aquí en adelante, y bajo el cobijo que nos brinda el diagnóstico originario de Hipócrates, podemos decir que esta historia psicológica de la melancolía se

1 "Si el temor y la tristeza perseveran mucho tiempo, esto indica melancolía." Hipócrates, "Aforismos," VI 23, en Tratados hipocráticos Vol. I: Juramento; Ley; Sobre la ciencia médica; Sobre la medicina antigua; Sobre el médico; Sobre la decencia; Aforismos; Preceptos; El pronóstico; Sobre la dieta en las enfermedades, ed. García Gual, C., Madrid, Gredos, 1990, p. 326.

2 Cfr., Aristóteles, Problema XXX, trad. Serna, C., Barcelona, Acantilado, 2007.

3 Cfr., Burton, R., Anatomía de la melancolia, Buenos Aires, Winograd, 2008.

4 Cfr., Galeno, Sobre las facultades naturales, trad. Zaragoza Gras, J., Madrid, Gredos, 2003.

5 Cfr., Ben Jonson., "Every Man in His Humour", en The Work of Ben Jonson, Oxford, ed. C. H. Herford, P. y E. Simpson, 1925-1952.

6 Cfr., Yllera, A., prólogo a Gargantúa, de François Rabelais, Madrid, Cátedra, 1999.

7 Cfr., Kant, I., Observaciones sobre lo bello y lo sublime, México, Fondo de Cultura Económica, 2004.

8 Los cuatro humores vendrían siendo: bilis, sangre, pituíta y bilis negra. Cfr. Hipócrates, Naturaleza del hombre VIII, 12, trad. Jesús de la Villa Polo et al., Madrid, Gredos, 2003, p. 52.

9 Isidoro, Etym., X, 176, trad. Cortés y Góngora, L., Madrid, B.A.C., 1951, p. 121. 
convertirá a su vez en una historia patologizadora de la melancolía, una historia nosológica de la bilis negra y, por lo tanto, una historia descalificadora de la misma. En efecto, esta es la tradición preponderante en nuestros días, y no es de extrañar; además de ese pequeño fragmento apenas notable en toda la extensión del corpus hipocratycus, el desarrollo de esta idea en el Medioevo desde un punto de vista médico, filosófico, teológico y hasta filológico, como vimos con San Isidoro, fue abrumadora. Por dar un par de ejemplos, Constantino el Africano (1010-1087), dice del melancólico que es "envidioso, triste, codicioso, avaro, desleal, triste y de tez terrosa" ${ }^{10}$, y el humor melancólico vendría siendo el "complejo más innoble"11. Podríamos mencionar además a Santa Hildegarda de Bingen, que relacionaba el «humor melancholicus» con la Caida del Hombre ${ }^{12}$; pero también a muchos otros como Gaspar Offhuys, Gordonius Brixiensis o el mismo Juan Crisóstomo, todos ellos con una visión satanizadora del melancólico.

Efectivamente, la historia que vincula la melancolía con lo áspero, la locura, el vicio, el pecado, el malestar y todo lo tétrico y fúnebre, es la que cobra más relevancia en nuestros días, y no solamente gracias a Hipócrates y el pensamiento medieval sino también a los estoicos que, en su afán de ejercitar la apatía como medio para conseguir la felicidad ataráxica, vieron en las emociones que producía la bilis negra un peligro latente para el sabio ${ }^{13}$. Ahora bien, sin ser considerada necesariamente un vicio o algo de cuidado, la historia que vincula la melancolía con la desazón continúa en el idealismo alemán, el romanticismo y se extiende hasta el siglo XIX, cobrando nuevamente un carácter patológico, en figuras que hicieron del fenómeno un concepto esencial como es el caso de Kierkegaard ${ }^{14}$, y así podríamos continuar hasta llegar a Freud ${ }^{15}$, que en total coherencia con la consideración primitiva del melancólico, triste y temeroso, volverá a revitalizar la idea del melancólico como un sujeto enfermo.

Podemos ver entonces, que esta "historia triste" de la melancolía pasa por momentos en donde es considerada como una enfermedad (los estoicos, el Medioevo, el Barroco alemán, Kierkegaard, Freud), pero también pasa por momentos donde, aunque conserva el principio de la aflicción, no es considerada precisamente una dolencia (Kant y el romanticismo, por dar un par de ejemplos). De esta manera, la "historia triste" de la melancolía ya no es necesariamente una "historia patológica", sino que ésta, la patológica, es un derivado posible de aquella otra, la triste. Pero hay otra matización importante en esta historia triste de la que hemos venido hablando, sea esta en su versión patologizadora o no, se trata de cómo en ésta, a veces, la melancolía es asociada a la posesión de un conocimiento particular, de un

10 Giehlow, C., en Walter Benjamin, El origen del Trauerpiel alemán, Madrid, Aabada, 2012, p. 143.

$11 \mathrm{Ib}$

12 “Cuando Adán pecó (...) la hiel se (le) mudó en amargor, y la melancolía en negrura de impiedad.” (Santa Hildegarda, en Raymond Klibansky, Erwin Panofsky, Fritz Saxl, Saturno y la melancolía, Madrid, Alianza, 2006, p. 97).

13 "la sabiduría y la locura eran mutuamente excluyentes: hasta el punto de que a todo el que no fuera sabio se le podía calificar de «loco»” (Raymond Klibansky, Erwin Panofsky y Fritz Saxl, Saturno y la melancolía, Madrid, Alianza, 2006, p. 65). No obstante, aunque el Sabio estuviera a salvo de la manía, podía curiosamente padecer un exceso de bilis negra; incluso según Diógenes Laercio, Crisipo decía que el Sabio podía perder su excelencia a causa de la melancolía (Diógenes Laercio, Vida de los filósofos, VII, Madrid, Alianza, 2010, p. 118).

14 Cfr., Adorno, Th. W., Kierkegaard, Madrid, Akal, 2006.

15 Cfr., Macías, M. A., Un estudio psicoanalítico sobre el duelo. El caso de la Emperatriz Carlota, México, Universidad Autónoma de Querétaro, 2002, p. 25. 
saber, de una verdad. Kant, por ejemplo, en sus Observaciones sobre lo bello y lo sublime, realiza una loa a la melancolía, relacionándola con la búsqueda auténtica del saber, con la rigurosidad del filósofo y además con la capacidad de experimentar lo sublime ${ }^{16}$. Los románticos, a finales del XVIII consideraban a la melancolía la principal inspiración para la creación artística. Kierkegaard creía, por su parte, que el atrabiliario se regocijaba en una verdad primitiva inmersa en la interioridad ${ }^{17}$. Y Freud, aunque considera la melancolía como "un estado profundamente doloroso, una cesación del interés por el mundo exterior (...) y la disminución del amor propio" 18 , confiesa, sin embargo, que el melancólico sí posee un saber, y que además tiene un deseo no inhibido de manifestar ese saber, dice Freud:

En otras de sus acusaciones, nos parece también tener razón, comprobando tan sólo, que percibe la verdad más claramente que otros sujetos, no melancólicos. Cuando en su autocrítica se describe como un hombre pequeño, egoísta, insincero y carente de ideas propias, preocupado siempre en ocultar sus debilidades, puede, en realidad, aproximarse considerablemente al conocimiento de sí mismo, y en este caso, nos preguntamos por qué ha tenido que enfermar, para descubrir tales verdades $(\ldots)^{19}$

Pero, ¿cómo llegamos de pronto a éste momento donde la melancolía, sea esta patológica o no, se hace portadora de un saber? Y además ¿cómo este fenómeno estigmatizado por la tristeza y el temor desde sus inicios logró evadir por momentos la tiranía patologizadora? ¿Acaso responde Freud a una tradición distinta a la de Kant o a la del romanticismo al usar el vocablo "melancolía” para referir una determinada enfermedad? ¿Pero qué tradición es esta si ambas posturas parecen seguir las huellas del miedo y la congoja? ¿Habrá territorios no explorados entre Hipócrates y los estoicos, entre el Medioevo y Kant, entre el Barroco alemán y Kierkegaard, entre los románticos y Freud, que nos permita comprender el brote repentino de esta valorización de la melancolía como portadora de alguna virtud o conocimiento? ¿Será que, a pesar de la persistencia del temor y la tristeza, este transcurso llegó a entrecruzarse con otra historia de la melancolía, una alterna e inclusiva, una abierta y propiamente filosófica, y se dejó “contaminar” en ocasiones por sus influjos? ¿Pero dónde y con quién podría comenzar una historia así? ¿Quién se atrevería a darle una oportunidad a ese complejo temible que es la "cólera oscura"? Se nos haría fácil pensar que sólo un poeta maldito, un atormentado de las letras, un libertino, un provocador, un Baudelaire con su spleen parisino ${ }^{20}$ se pondría con el ejercicio retórico de defender lo que ya en su nombramiento parece despreciable: "bilis" "negra". Sin embargo, el arquitecto de los pilares de esta historia alterna de la melancolía no se parece en lo más mínimo a un dandi del XIX. Se trata del urbanizador intelectual de la Grecia Antigua, del filósofo de la moderación y "justo medio", del menos "espiritual" de los filósofos antiguos, dirá Foucault; hablamos de Aristó-

16 Cfr., Kant, I., Observaciones sobre lo bello y lo sublime, Op.cit.

17 "Pero yo no renuncio a las ideas extrañas de mi melancolía (...) Por eso estimo tanto estas ideas en mi soledad, a pesar de que ya me asustan" (Kierkegaard en Adorno, Th. W., Kierkegaard, Madrid, Akal, 2006, p. 79).

18 Freud, S., "Duelo y melancolía”, en Obras completas, ed. Etcheverry, J. L., Buenos Aires, Amorrortu, 19781985 , p. 2091.

19 Ib., p. 2092.

20 Cfr., Baudelaire, C., El spleen de París (pequeños poemas en prosa), Madrid, Susaeta, 1994. 
teles. En su Problema $X X X$, se hace una fascinante exploración en torno al vínculo existente entre el hombre de genio y la bilis negra. El pequeño opúsculo aristotélico comienza con la siguiente pregunta:

¿Por qué razón todos, aquellos que han sido hombres de excepción, bien en lo que respecta a la filosofía, o bien a la ciencia del Estado, la poesía o las artes, resultan ser claramente melancólicos, y algunos hasta el punto de hallarse atrapados por las enfermedades provocadas por la bilis negra, tal y como explican, de entre los relatos de tema heroico, aquellos dedicados a Heracles? ${ }^{21}$

Esta formulación implica dos suposiciones: en primer lugar todo hombre excepcional ${ }^{22}$ padecería de un exceso humoral; y en segundo lugar, la bilis negra sería el humor causante de un exceso relacionado con el furor o la manía. El melancólico, según el Problema $X X X$, no estaba más propenso al temor o la depresión, que a la temeridad o el entusiasmo. Lo que realmente distingue el carácter melancólico, según Aristóteles, es la extrema movilidad, la rapidez de sus alteraciones. La melancolía, tal cual la explica el estagirita, no es una sustancia necesariamente nociva para los hombres y aunque no excluye los fenómenos del miedo y la congoja a los que hace alusión el fragmento hipocrático, tampoco la limita a estos, lo que permite una apertura de su comprensión. Incluso figuras de gran importancia dentro del pensamiento mítico como: Ajax, Belerofonte y Heracles, son calificados como melancólicos, y también los grandes filósofos de la Antigüedad, tal es el caso de Sócrates y, el maestro del mismo Aristóteles, Platón. De esta manera, la melancolía vendría a relacionarse en el Problema $X X X$ con la lucidez, la excepcionalidad y la sensibilidad adquiriendo un contenido nuevo y positivo, desde donde fue posible reconocer y explicar a la vez el fenómeno del "hombre genial".

Así, Aristóteles inaugura una concepción del melancólico donde éste no se presenta necesariamente triste y aletargado, y es justamente este "no necesariamente" la marca que distingue la "historia alterna" de la melancolía que el estagirita inicia. No obstante, frente a la máxima hipocrática, iniciadora de todo este sistema humoral-temperamental, y después la consideración de los estoicos, la teología medieval y el psicoanálisis ¿cómo podría justificarse este enunciado peripatético donde el melancólico es tan propenso a la tristeza como a la alegría desbordada o a la lujuria desenfrenada? Recordemos que la doctrina médica hipocrática estaba constituida por cuatro sustancias esenciales: una seca y caliente que es la bilis, una húmeda y caliente que es la sangre, otra seca y fría que es la bilis negra, y finalmente una húmeda y fría que es la flema. Hay tres textos fundamentales en la protohistoria de la teoría de los temperamentos galénicos que convertirá estos cuatro humores de la medicina hipocrática en estados de ánimo o tipos psicológicos. Es curioso que los tres textos que permitieron este paso de lo meramente somático-nosológico a lo psicológico giran en torno al problema de la melancolía. De estos tres textos ya hemos mencionado dos, el fragmento hipocrático y el Problema $X X X$, el otro que no hemos mencionado es el intercambio epistolar

21 Aristóteles, Problema XXX, 953a 10, trad. Serna, C., Barcelona, Acantilado, 2007, p. 79.

22 Es así como Pigeaud traduce el término: perittoi (Pigeaud, J., prólogo a El hombre de genio y la melancolía (problema XXX), de Aristóteles, Barcelona, Acantilado, 2007, p. 20. 
pseudohipocrático ${ }^{23}$. En estas epístolas se narra la visita de Hipócrates a Demócrito quien, según el pueblo de Abdera, se encuentra en un estado de locura y los síntomas que han preocupado a los abderitas son varios: Demócrito se ha retirado de los asuntos públicos, pasa largos periodos de tiempo totalmente solo mientras lee libros y diseca animales, dice cosas extrañas e incomprensibles y, finalmente, además de ser también lo más preocupante, una constante y estrepitosa risa le surge incluso frente a las noticias más trágicas ${ }^{24}$. Sin embargo, casi nada de lo que le escribe el Senado de Abdera sobre Demócrito preocupa a Hipócrates, excepto una sola cosa que le lleva a la conclusión de que Demócrito padece un exceso de bilis negra: se trata de su risa desembocada que no distingue lo gracioso de lo trágico. Sobre este texto debemos decir tres cosas:

Primero, vemos cómo aquí nos encontramos de nuevo con un texto que vincula un exceso humoral con un estado psicológico particular, y además vemos cómo ese exceso humoral se trata específicamente de la bilis negra. Segundo, vemos cómo algunas características típicas del melancólico vuelven a aparecer pero esta vez en la figura de Demócrito, tales como: la locura, el apartarse de los asuntos sociales y el interés por los asuntos intelectuales. El tercer punto, y el más destacable, es que si bien se describen algunos síntomas que la tradición había relacionado con la melancolía, lo único que Hipócrates ve como un verdadero síntoma que podría llevar al diagnóstico de la melancolía es el carcajeo. Nos permitiremos decir que aquí aparece repentinamente un texto bastante antiguo el cual vincula la melancolía con un fenómeno muy distante, por no decir contrario, a la tristeza y el aletargamiento. Ahora bien ¿qué estímulos llevaron a los creadores del Problema $X X X$ y de las cartas pseudohipocráticas a distanciar la bilis negra de la tristeza, el miedo y el letargo? Mejor preguntémoslo así: si el hombre con exceso natural de bilis negra se caracterizaba por ser afligido y adormecido, ¿cómo eran los hombres con exceso de algún otro humor?

Según Galeno, los que tenían un exceso de sangre eran los más simples y estúpidos, sin embargo más alegres, muy activos y nada proclives a la cólera. Los coléricos serían finos e inteligentes, irascibles, audaces, impetuosos, con sentidos exactos, muy despiertos, dados a la acción, fogosos, rápidos, violentos, toscos, desvergonzados y tiránicos en sus costumbres. Los pituitarios serían, por su lado, perezosos y más estúpidos, carecerían de carácter, con el cerebro adormecido, soñolientos, timoratos, cobardes y, al igual que los sanguíneos, nada proclives a la cólera ${ }^{25}$. Podemos ver aquí que las características mencionadas por Galeno del hombre con exceso de flema coinciden con las características que da el Medioevo, el Barroco alemán e incluso el psicoanálisis del melancólico. La relación que hacen los teólogos entre el perezoso, el que tiene acedia y el que es melancólico, debería, según el sistema de los cuatro temperamentos, ser vinculado más bien con el flemático. Además, las características de temeroso y cobarde, que habían sido tan constante en las descripciones del melancólico,

23 Cfr. Hipócrates, Do Riso e da Loucura, Padrões Culturais, Lisboa, 2009.

24 "Se olvida de todo hasta del él mismo, Demócrito permanece ahora día y noche despierto, descubriendo en cualquier cosa grande o pequeña motivo para reír y divulgando que la vida no tiene ningún valor. Unos se casan, otros ejercen el comercio, estos dan discursos al pueblo, aquellos gobiernan, algunos parten a la embajada, hacen elegir o destituir, caen enfermos, son heridos, mueren: Demócrito se ríe de todo, viendo a unos tristes y atormentados y otros repletos de júbilo" (Hipócrates, Do Riso e da Loucura, Padrões Culturais, Lisboa, 2009, pp. 25-26).

25 Galeno en Raymond Klibansky, Erwin Panofsky y Fritz Saxl, Saturno y la melancolía, Madrid, Alianza, 2006, pp. 80-83. 
dentro del sistema humoral tendría que ser algo propio de los que tienen un exceso de humor frio y húmedo. El que la melancolía permita un incremento de las capacidades intelectivas y la pituita todo lo contrario, tiene explicaciones de carácter médico-humorales. Desde tiempos de Heráclito la humedad siempre ha estado ligada con la estupidez, y esto se mantuvo con Hipócrates y Galeno, hasta el Renacimiento. En ese sentido el sujeto con un exceso de humor húmedo y frio siempre será más propenso a la sandez que el hombre con exceso de un humor seco y frio como lo es la bilis negra. De hecho, Galeno describe al melancólico de esta manera: "el que tiene exceso de bilis negra es firme y sólido, más irascible y desvergonzado, en la juventud sus sentidos son exactos y absolutamente irreprochables" 26 . Frente a estos perfiles, no es absurdo preguntarse si aquella historia peyorativa de la melancolía, no es apenas el fruto de una disolución de las fronteras que distinguían al atrabiliario del pituitario. Panofsky, Klibansky y Saxl dicen con respecto al melancólico dos cosas:

Primera: que con el paso del tiempo este humor "terroso", que para Galeno era la fuente de la firmeza y la constancia, se fue cargando cada vez más de propiedades desfavorables, y segunda, que sus características empezaron a fundirse con las del flemático; al final serían intercambiables (...) Se ve que las ideas de "flemático" y "melancólico" se entremezclaron, y que esta confusión fue rebajando el status de la disposición melancólica hasta que ya apenas quedó nada bueno que decir de ella ${ }^{27}$.

No obstante, el triunfo de esta identificación confusa en nuestra concepción contemporánea de la melancolía, no significa que aquella otra forma de entender la bilis negra no haya tenido su propia relevancia histórica más allá de Aristóteles y las precisiones galénicas. En el siglo XV, el filósofo y médico Marsilio Ficino, totalmente al tanto de la medicina hipocrática, el sistema temperamental galénico y el Problema $X X X$ aristotélico, realiza un elogio al temperamento melancólico al cual identifica con la dedicación a las letras, la filosofía y el ejercicio contemplativo ${ }^{28}$. El autor florentino, por ser especialmente afín a la filosofía platónica, relaciona el hombre de genio melancólico de Aristóteles, con el furor del que habla Platón, que se presenta como una especial disposición para con la verdad. En la escena isabelina, por otra parte, la melancolía mantuvo su dignidad en tanto temperamento que predisponía a la verdad e incluso a la belleza, disposición anímica tan valorada que incluso era usual fingir tenerla. En Every Man in His Humour, Ben Jonson nos brinda este diálogo:

- Primo, ¿estoy bien así? ¿Estoy lo bastante melancólico?

- Ah, es el más bello de los humores, señor; la melancolía verdadera engendra una gracia perfecta, señor ${ }^{29}$.

Y es justamente en el teatro isabelino donde quizás encontremos a la figura más representativa de esta historia abierta de la melancolía: Hamlet. El príncipe de la tragedia shakesperiana, actúa como si estuviera "afectado" de una forma particular, no se sabe bien si entre la

$26 I b .$, p. 83.

27 Ib., p. 85.

28 Ficino, M., Tres libros sobre la vida, Madrid: Asociación española de neuropsiquiatría, 2006, p. 27.

29 Ben Jonson., "Every Man in His Humour", Op. cit., p. 354. 
tristeza, lo lunático o lo extático, como se atreve calificarlo Polonio; o si más bien bastaría con llamarle melancólico, como lo hace Claudio cuando dice: "Hay algo en su alma / que alimenta su melancolía" ${ }^{30}$. Pero Guildenstern cree que la disposición de Hamlet es la de una tristeza tanto astuta como fingida; y el mismo Hamlet le dice a su madre que, según el rey, él está "loco sólo por astucia"31. Hay que recordar que el protagonista de la obra, en vez de obrar rápidamente y matar al asesino de su padre, éste prefiere "asumir una disposición histriónica"32. Esto parece una actitud completamente descabellada, sin embargo, gracias a que toma el papel de bufón de la corte, puede burlar la vigilancia de Claudio, maniobrar a hurtadillas y, al mismo tiempo, emitir, sin temor a las represalias, verdades sobre el mundo corrupto en el que vive. Que Hamlet actúe, en tanto que toma un papel, como un bufón enloquecido, no quiere decir, sin embargo, que él realmente no siente lo que hace, ya que el papel que él representa es el de sí mismo: “¿«Parece», señora? (...) ¡Yo no sé parecer!”33. Imita su propia locura y, al imitarla, encuentra cierta libertad en relación con las potencias anímicas que lo corroen. Al identificarse con esas mismas potencias, Hamlet amplía su radio de acción y las traslada al plano lingüístico. En palabras de Pollock: "La bilis negra alimenta los cimientos cerebrales de su pensamiento, desvía las operaciones formales que presiden la creación de nuevas frases, libera secuencias inéditas, encadenamientos descabellados, asociaciones cómicas" 34 . Aquí vemos cómo el "desequilibrio melancólico" se convierte en potencial e inspiración creativa, incluso humorística, en la figura de Hamlet.

Cuando se nos presenta el encuentro del príncipe con el cráneo del difunto bufón del rey, Yorick, entonces comprendemos el ambivalente carácter de la melancolía del protagonista de la obra, entre la tristeza y la hilaridad. Yorick es el "padre de juegos" del joven Hamlet, en oposición al "padre de ideales" que representaba el rey difunto, el príncipe decide adoptar la actitud de su padre bufón, pero llevando consigo el duelo que le ocasiona su muerte. La vista del cráneo le inspira al príncipe, primero compasión, luego repugnancia y después, indefectiblemente, una actitud burlona. El bufón encuentra nuevamente a alguien que se ríe de sus muecas. Hamlet se transforma en una figura activa de la melancólica, en la disidencia humorística, incluso dentro de la tragedia. Ya no es posible pacto alguno, Hamlet se divierte en grande con las desgracias del destino. Shakespeare no ablanda o endulza a los ojos del espectador la melancolía del personaje principal, más bien la ensalza con una hilaridad corrosiva, la risa ante la muerte se convierte en el himno triunfal de la melancolía; así, cuando el rey pregunta dónde está ya difunto Polonio, Hamlet le responde: "De cena". Claudio, estupefacto, lo interroga nuevamente y Hamlet precisa: "No donde come, sino donde es comido". Y cuando, finalmente revela el lugar donde yace el cadáver, agrega con tono burlón: "Ya esperará hasta que lleguéis"35.

Aunque Hamlet se presenta como la figura radical de esta historia abierta de la melancolía, no por ello esta historia termina aquí. También el siglo de oro español, el surrealismo francés, el teatro del absurdo y el humorismo de todos los tiempos son expresiones que

30 Hamlet., 2.1., pp. 165-166

31 Ibid., 3.4., p. 177.

32 Ibid., 1.5., p. 179.

33 Ibid., 1.2., p. 76.

34 Pollock, J., Op. cit., p. 71.

35 Hamlet., 4.3., p. 38. 
cuestionan la visión patologizadora de la melancolía, así como la visión lúgubre de la misma, agregando el plus de un saber o una sensibilidad especial por el saber. Es cierto que Freud en Melancolía y duelo considera un fenómeno psíquico que, a pesar de ser sintomáticamente opuesto a lo que él mismo describe como melancolía, le parece que suele brotar de ésta; se trata de la manía. En la manía al igual que en la melancolía, se da en principio una identificación del Yo con el objeto fallido sobre el que se tenía la carga libidinal, pero si en la melancolía el Yo se mantiene sojuzgado por la instancia crítica del Yo que castiga sádicamente por la identificación con el objeto fallido que tenía la carga libidinal, en la manía, al contrario, el Yo logra liberarse de la identificación con el objeto fallido que causaba el dolor, y en esta economía del dolor esperado se da un placer desinhibidor del $\mathrm{Yo}^{36}$. Podría Freud identificar uno de los extremos de la melancolía aristotélica como momento melancólico y el otro como momento maníaco, uno representado en el llanto de Heráclito o la tristeza hamletiana y otro en la carcajada de Demócrito o el histrionismo del personaje shakesperiano. No es casualidad que el único personaje literario al que hace alusión Freud en Melancolía y duelo es justamente Hamlet ${ }^{37}$. En Hamlet el luto es evidente en relación a la muerte del padre, la melancolía es recurrente durante toda la obra en las descripciones que hacen los personajes secundarios del príncipe e incluso en algunas metáforas que expresa éste sobre sus propios delirios, y sus actitudes hilarantes puede que tengan cabida dentro de lo que Freud llama "un momento maníaco" en alternancia con la melancolía.

No obstante, la manía por sí sola no explica la lucidez y aún menos la expresión humorística que más que una patología es, para el psicoanalista vienés, "el más grandioso de los mecanismos defensivos" 38 . Curiosamente, para Freud en la melancolía y en el humor se da una dinámica semejante: en el caso de la melancolía la instancia crítica del Yo (Super-yo) inflamado de energía efectúa una cruel supresión del Yo. En el humor, en cambio, aunque el sujeto deposite la energía en el Super-yo éste, contra todo pronóstico, no castigar al Yo sino que lo consuela, y a su vez logra liberarse por ello ${ }^{39}$. No es mera casualidad que la historia abierta de la melancolía gusta de caminar al lado del humor; Klibansky, Panofsky y Saxl dicen que el humor es un fenómeno que sólo pudo surgir en el momento en que la melancolía encuentra su modo de expresión literaria ${ }^{40}$. Y el psicoanalista Paul-Laurent Assoun, dice al respecto que "el humor funciona como filtro de la angustia de muerte y es más una formación reactiva de la disposición melancólica" ${ }^{41}$. ¿Por qué debiera extrañarnos que el humor negro haga referencia a la melancolía, al único humor (fluido corporal) que es negro en el humoralismo hipocrático?

No es la dialéctica manía-melancolía la que nos permite comprender la conexión entre la concepción abierta de la melancolía de Aristóteles y la patológica de Freud. Es la confusión histórica entre melancolía y flema, y el análisis freudiano del humor los que nos darán nuevas pistas para comprender el confluir de las dos historias. ¿No tiene acaso el melancó-

36 Freud, S., "Duelo y melancolía", Op. cit., p. 2093.

$37 \mathrm{Ib}$.

38 Freud, S., "El humor," en Sigmund Freud. Obras completas, Vol. XXI, ed. José Luis Etcheverry, Buenos Aires, Amorrortu, 1978-1985, p. 4.

39 Ib., p. 6.

40 Klibansky, Erwin Panofsky, Fritz Saxl, Saturno y la melancolía, Op. cit., p. 254.

41 Assoun, P. L., “L'Inconscient humoriste," en L'Humour, 131 (Septiembre de 1992): pp. 51-68. 
lico una facilidad extraordinaria para la creación humorística claramente relacionada con la lucidez? ¿Por qué la patología de la manía y no el mecanismo grandioso de lo humorístico? ¿No habrá subestimado Freud las capacidades de la estructura Yoica en el momento que se manifiesta tan débil y miserable como es el caso de la melancolía y el humor? Dice Deleuze al respecto: “ ¡Cuánta irrisión y cuanto humor, que revuelta invencible y que triunfo se esconden bajo un Yo que se confiesa tan débil! La debilidad del Yo es la trampa ya tendida"42.

¿Qué melancolía más lúcida y claramente humorística que la de San Lorenzo Mártir mientras estaba siendo incinerado en una brasa? "Dadme vuelta, que por este lado ya estoy cocido".

\section{Bibliografía}

Adorno, Theodor (2006): Kierkegaard, Madrid, Akal.

Aristóteles (2007): Problema XXX, Barcelona, Acantilado.

Baudelaire, Charles (1994): El spleen de París (pequeños poemas en prosa), Madrid, Susaeta.

Benjamin, Walter (2012): El origen del Trauerspiel alemán, Madrid, Aabada.

Burton, Robert (2008): Anatomía de la melancolía, Buenos Aires, Winograd.

Deleuze, Gilles (2011): La Lógica del Sentido, Madrid, Paidós.

Diógenes Laercio (2010): Vida de los filósofos, Madrid, Alianza.

Ficino, Marcilio (2006): Tres libros sobre la vida, Madrid, Asociación española de neuropsiquiatría.

Freud, Sigmund (1978-1985): Obras completas, Buenos Aires, Amorrortu.

Galeno (2003): Sobre las facultades naturales, Madrid, Gredos.

Hipócrates (1990): Tratados hipocráticos Vol. I: Juramento; Ley; Sobre la ciencia médica; Sobre la medicina antigua; Sobre el médico; Sobre la decencia; Aforismos; Preceptos; El pronóstico; Sobre la dieta en las enfermedades, Madrid, Gredos.

Hipócrates (2003): Naturaleza del hombre, Madrid, Gredos 2003.

Hipócrates (2009): Do Riso e da Loucura, Padrões Culturais, Lisboa.

Isidoro (1951): Etimologías, Madrid, BAC.

Jonson, Ben (1925-1952): "Every Man in His Humour", en The Work of Ben Jonson, Oxford, ed. C. H. Herford, P. y E. Simpson.

Kant, Immanuel (2004): Observaciones sobre lo bello y lo sublime, México, Fondo de Cultura Económica.

Klibansky, Raymond; Erwin Panofsky y Fritz Saxl (2006): Saturno y la melancolía, Madrid, Alianza.

Macías, Marco Antonio (2002): Un estudio psicoanalítico sobre el duelo. El caso de la Emperatriz Carlota, México, Universidad Autónoma de Querétaro.

Pollock, Jonathan (2003): ¿Qué es el humor? Buenos Aires, Paidós.

Rabelais, François (1999): Gargantúa. Madrid, Cátedra.

Shakespeare, William (2005): Hamlet, edición bilingüe ingles/castellano, Madrid, Cátedra, 2005.

42 Deleuze, G., Presentación de Sacher-Masoch. Lo frío y lo cruel, Buenos Aires, Amorrortu, 2008, p. 92. 